\title{
HUMIDITY SENSING POTENTIAL OF
}

\section{A MICROCRYSTALLINE CELLULOSE SHEET}

\author{
ANNE D. FERNANDOPULLE, ${ }^{*}$ LALEEN KARUNANAYAKE, DON A. S. AMARASINGHE, ${ }^{* *}$ \\ ADIKARI M. P. B. SAMARASEKARA** and DINESH ATTYGALLE** \\ *Department of Polymer Science, University of Sri Jayewardenepura, Nugegoda 10250, Sri Lanka \\ ${ }^{* *}$ Department of Materials Science and Engineering, University of Moratuwa, \\ Katubedda, Moratuwa 10400, Sri Lanka \\ \orresponding author: A. M. P. B. Samarasekara, banduamp@gmail.com
}

Received January 23, 2021

Generally, physical objects connected to the internet, directly communicating with others, are limited to personal computers and smartphones. However, with the advent of IoT, many other physical objects will interconnect and communicate through the internet, enabling the automatic and remote control of the environment. The effectiveness of this system will depend on our ability to collect data on the environment. Transducers are materials that gather information about the environment and transform it into electrical signals. Therefore, the discovery of potential transducer materials has become the need of the hour.

In this study, we investigate the potential of a microcrystalline cellulose (MCC) sheet for remote humidity sensing. The variation in MCC's incremental moisture adsorption with relative humidity shows a sharper change at higher humidities, comparable to tropical climatic conditions. The findings of the study reveal that the relative humidity (RH) changes can be converted to electrical signals by an MCC sheet, and the linearity of this transduction depends on the frequency. The highest linearities can be obtained at lower frequencies, and the level of sensitivity of this transducer also depends on the frequency. Better sensitivities are observed at lower frequencies. Therefore, the MCC-sheet transducer is more appropriate for remote sensors operating at lower frequencies.

Keywords: transducers, MCC, capacitance, humidity sensing, Internet of Things

\section{INTRODUCTION}

Natural materials are the primary source of all technological products. Besides minerals and petroleum, plants are the other largest source of natural materials. ${ }^{1}$ Plant-derived cellulose holds a vital position as the most abundant natural biopolymer on the earth. ${ }^{2-6}$ The cellulose polymer is composed of D-glucose units linked through $\beta(1-4)$ glycosidic bonds (Fig. 1). The mechanical properties of cellulose, and specifically, those of microcrystalline cellulose (MCC) fibers have been widely investigated. The results recommend microcrystalline cellulose as a good reinforcing filler for polymer composites. ${ }^{7-23}$

Though cellulose is a cost-effective dielectric material, with a dielectric constant between 3.27.5, the application of MCC in the field of electrical technologies is limited..$^{20-24}$ This is mainly because the electrical characteristics of microcrystalline cellulose are not known well enough yet. Understanding these properties is important in finding engineering applications for these materials. ${ }^{25}$ As all dielectrics, though their electrical conductivity is very low, ${ }^{26}$ they get polarized in an electric field. The polarization of dielectrics can occur due to various mechanisms. When a dielectric is subjected to an electric field, its charge distribution changes and becomes aligned with the external field. ${ }^{27}$ Due to this, a capacitor can store energy in the form of an electric field. When a dielectric is subjected to an AC field, instead of an external DC electric field, the dipole alignments of the dielectric will respond to the external field variations. The AC dielectric constant depends upon the frequency of the applied field, temperature, and chemical or physical structure of the material. ${ }^{28}$ 
The ratio of the capacitance of a dielectricfilled capacitor to the vacuum or air-filled capacitor is recognized as a measure of polarization of the dielectric and is also called dielectric constant: ${ }^{29}$

$\epsilon_{r}=\frac{C}{C_{\text {vac }}}$

Recent developments in the area of Internet of Things (IoT), which connects objects to the worldwide network, have opened new perspectives, raising the interest in materials properties. The IoT has created a demand for developing or re-engineering materials as smart functional devices that can gather information about the environment..$^{30,31}$ Easy to make, flexible and cheap, natural materials are the best candidates for these purposes, ${ }^{32}$ and MCC does fulfill all the required criteria. ${ }^{33}$ Also, it can be easily converted into paper form, and paper is widely used as a packing material. ${ }^{34}$ Hence, if MCC based paper is converted into an active device, which can gather information about its environment, it will be very useful in the present context.

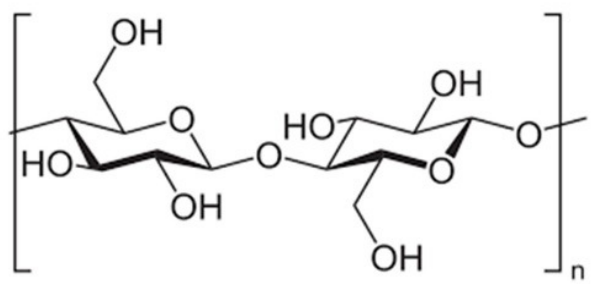

Figure 1: Chemical structure of cellulose

In this work, MCC-based transducer materials are studied in detail to explore their potential as capacitive humidity sensors. Tropical climates are the most challenging environment to control humidity, and these hot and humid conditions pose challenges in protecting food, drugs, and electronic and optical devices from moisture attacks. The incremental moisture adsorption of MCC with relative humidity shows a sharper variation at higher humidity levels than regular cellulose. With this property and its lower cost, compared to nano-sized cellulose, it is interesting to know how well the moisture sensitivity of MCC can be converted to an electrical signal, as there is lack of published literature in this area. This investigation focuses on the responses of MCC sheet transducer materials to $\mathrm{RH}$, in terms of accuracy and sensitivity, under tropical environmental conditions. ${ }^{20,35,36,37}$

\section{EXPERIMENTAL}

\section{Raw materials}

MCC was received from Sisco Research Lab. Pvt. Ltd., India. Sodium chloride $(\mathrm{NaCl})$ and $99.5 \%$ potassium chromate $\left(\mathrm{K}_{2} \mathrm{CrO}_{4}\right)$ were purchased from LOBA Chemie Pvt. Ltd, India. 99\% Sodium nitrate $\left(\mathrm{NaNO}_{3}\right), \quad 99.5 \%$ potassium iodate $\left(\mathrm{KIO}_{3}\right), 99 \%$ sodium sulfate anhydrous $\left(\mathrm{Na}_{2} \mathrm{SO}_{4}\right)$, from DAEJUNG Chemicals, Korea, and $99.5 \%$ sodium hydrogen carbonate $\left(\mathrm{NaHCO}_{3}\right)$, from Fluka Chemie, were used for the preparation of saturated salt solutions.

\section{MCC sheet preparation}

A suspension of microcrystalline cellulose was prepared, using hot distilled water, and was subjected to intense beating. After that, a pulp was obtained and it was spread to form sheets, according to the standard SCAN-CM 64:00 (Scandinavian Pulp, Paper and Board Testing Committee) method for the preparation of laboratory sheets. ${ }^{20}$ In the original method, flatmetal drying plates, blotters (contained no wet strength agents), and a template (to facilitate the positioning of the sheets) were used. The sheet former with a drainage valve, as per the original method, was replaced with a wooden frame and a microscale pore mesh. The sample was dried using the blotters and pressure plates. The compression pressure of $400 \pm 10$ $\mathrm{kPa}$ was applied evenly for 3 minutes at $100{ }^{\circ} \mathrm{C}$ and then sheets were kept under reduced pressure, of about $3 \mathrm{kPa}$, for $48 \mathrm{~h}$ to prevent shrinking. The sheets were removed from the drying plates and cut to the desired dimensions (in this case, of $22 \mathrm{~mm} \times 23 \mathrm{~mm}$ ). Except some specified steps, all the other procedures were carried out at room temperature $\left(25^{\circ} \mathrm{C}\right)$.

\section{Capacitance measurements}

A parallel plate capacitor was made with two copper plates sandwiching the MCC sheet. The capacitance value of this fabricated capacitor was measured under different humidity conditions, using an 
LCR (inductance - capacitance - resistance) tester at different frequencies.

Different humidity conditions created with saturated salt solutions

Solubility data for the salts used, at $25{ }^{\circ} \mathrm{C}$, were obtained from an online reference. ${ }^{20,39}$ All the solutions were prepared using Milli-Q water. $200 \mathrm{~mL}$ of Milli-Q water was mixed with the appropriate amount of salt to make a saturated salt solution under vigorous stirring. The saturated solutions and a sample piece of the MCC sheet were kept in an enclosed system at room temperature. This procedure ensured the equilibrium of water vapor with the solution.

The mass of the MCC sample was measured at certain time intervals until it became constant. This occurs when the system has reached equilibrium ${ }^{40}$ and, the vapor pressure of the enclosed environment is equal to the saturated vapor pressure of the salt solution. The saturated vapor pressure data of these solutions were obtained from the literature. They were regressed with the capacitance of the MCC sheets to examine the response of MCC.

\section{RESULTS AND DISCUSSION \\ Dielectric behavior of MCC sheets}

The AC capacitance of an MCC sheet shows an exponential decay type variation with frequency. The AC capacitance of the MCC sheet samples, with varying thicknesses, was measured at different frequencies, ranging from $50 \mathrm{~Hz}$ to 5 $\mathrm{MHz}$. The capacitance-frequency variations are given in Figure 2. It is worth noting that the $\log$ frequency values are plotted against the capacitance. As expected, the capacitance values at all frequencies depend on the sheet thickness.

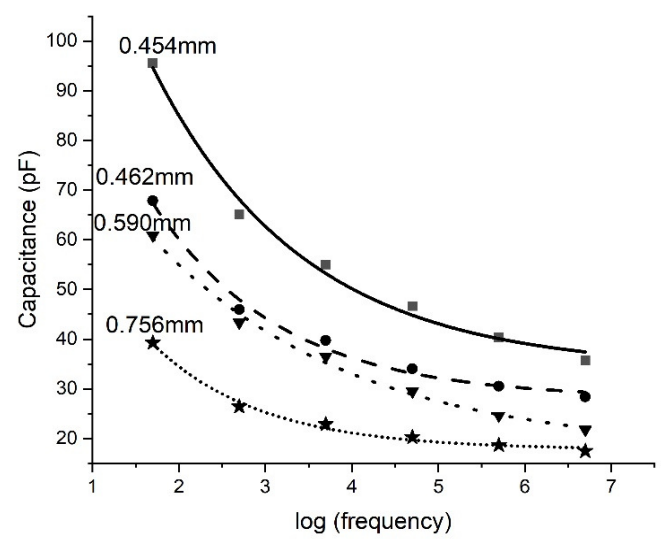

Figure 2: Capacitance values of four MCC sheets (thickness of $0.454 \mathrm{~mm}, 0.462 \mathrm{~mm}, 0.590 \mathrm{~mm}, 0.756$ $\mathrm{mm}) ; \log$ frequency values are used in the horizontal axis

\section{Effect of moisture on dielectric behavior}

The MCC sheet adsorbed a fair amount of moisture when exposed to ambient conditions (Fig. 3). ${ }^{11,41}$ The equilibrium moisture content adsorption and desorption isotherms of cellulose and microcrystalline cellulose show sigmoidal variation with RH, typical of cellulosic materials. $^{42}$ The incremental change in moisture content with RH curve shows that MCC displays sharper variation above RH $85 \%$, compared to regular cotton. ${ }^{42}$ This $\mathrm{RH}$ range is typical of tropical climates.

The moisture adsorption has a direct effect on the dielectric properties of an MCC sheet. The dielectric constant of a material is a function of temperature and frequency. ${ }^{28}$ The moisture effect on the dielectric behavior of the MCC sheet is clearly visible in the variations depicted in Figure 3. The data show a significant dielectric enhancement after moisture adsorption. For example, the desorption of adsorbed moisture by vacuum reduces the dielectric constant by about $30 \%$. This observation confirms the potential of MCC as a transducer material for capacitive sensors.

The MCC sheet shows two significant steps of weight loss due to thermal degradation. ${ }^{43,44}$ In the first step, a small weight loss was observed below $100{ }^{\circ} \mathrm{C}$ due to the removal of absorbed water and other volatiles (Fig. 4). ${ }^{45}$ Moisture adsorption onto the MCC sheet could take several mechanistic paths and, thereby, it displays different binding affinities, such as tightly bound, loosely bound and bulk water. ${ }^{46}$

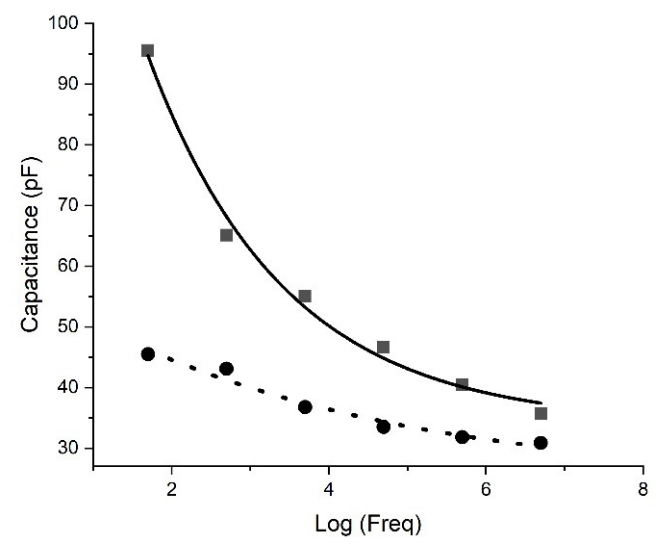

Figure 3: Capacitance variations of vacuumed (circles) and non-vacuumed (squares) MCC samples 


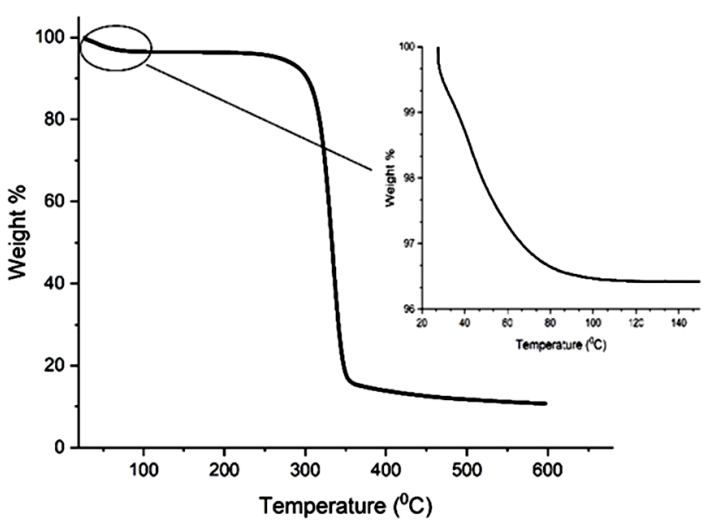

Figure 4: TGA thermogram of MCC

Table 1

Vapor pressure data at $25{ }^{\circ} \mathrm{C}(298 \mathrm{~K})$

\begin{tabular}{lccc}
\hline Salt & $\begin{array}{c}\text { Solubility } \\
\text { per } 100 \mathrm{~g} \mathrm{of} \mathrm{H}_{2} \mathrm{O}(\mathrm{g})\end{array}$ & $\begin{array}{c}\text { Vapor pressure } \\
\text { at } 25^{\circ} \mathrm{C}(\mathrm{kPa})\end{array}$ & $\begin{array}{c}\text { Relative humidity } \\
\text { at } 25^{\circ} \mathrm{C}(\%)\end{array}$ \\
\hline $\mathrm{NaCl}$ & 26.45 & 2.48 & 77.74 \\
$\mathrm{KIO}_{3}$ & 9.16 & 3.0814 & 96.59 \\
$\mathrm{NaNO}_{3}$ & 88.00 & 2.383 & 74.70 \\
$\mathrm{Na}_{2} \mathrm{SO}_{4}$ & 21.94 & 3.08 & 96.55 \\
$\mathrm{~K}_{2} \mathrm{CrO}_{4}$ & 65.00 & 2.75 & 86.50 \\
$\mathrm{NaHCO}_{3}$ & 9.32 & 3.18 & 99.68 \\
$\mathrm{H}_{2} \mathrm{O}$ & - & 3.19 & - \\
\hline
\end{tabular}

At first, water molecules connected with the hydroxyl $(\mathrm{OH})$ groups on two carbon six (C-6) atoms in the cellulose structure, which are in the amorphous region of cellulose. ${ }^{46}$ Consequently, at low humidity, the adsorbed water molecules bind tightly to the cellulose, however at higher relative humidity (RH) values, molecules lose their binding strength. ${ }^{46}$ Under these high $\mathrm{RH}$ conditions, hydrogen bonds between cellulose chains collapse to accommodate more water molecules. ${ }^{46}$ When the RH is as high as $60 \%$, adsorbed water molecules tend to bind with other water molecules, and the result is a loosely packed bulk liquid phase. ${ }^{46}$

The permittivity (or the dielectric constant) of a material represents its ability to polarize in response to an applied field. The loosening of polar groups at higher $\mathrm{RH}$, therefore, could also assist the dielectric constant increase. ${ }^{47}$ The other possibility for this increase is the discharge of the ions in the cellulose fiber at higher $\mathrm{RH}^{47}$

\section{Potential of the MCC sheet as a transducer material}

A parallel plate capacitor was made using the MCC sheet as a dielectric material, as described in the experimental procedure, and capacitance values were measured under different humidity conditions. Table 1 summarizes the saturated vapor pressure values and the corresponding relative humidity (RH\%) values ${ }^{48,49,50,51}$ of the six different salt solutions used in this experiment.

\section{Selecting frequency for the sensor}

This transducer material is meant to convert $\mathrm{RH}$ value changes to an electrical signal (capacitance). Though the linear response is always preferred, ${ }^{52}$ almost all transducers associate with some non-linearity in their responses. These non-linearities could lead to providing non-accurate linear equivalents. In actual applications, the tolerable degree of error varies. However, it is vital to understand the inherent non-linearities of the transducer response in sensor designing.

Therefore, the collected capacitance values (at different $\mathrm{RH}$ ) were linearly regressed on $\mathrm{RH}$ values, and the results are shown in Figure 5. The goodness of fit, R-squared, can be used as a measure of transducer response linearity. ${ }^{52}$ According to Figure 6, lower frequencies provide 
more linear responses, and with the increase of frequency, linearity exponentially decreases.

The sensitivity of a transducer is another vital parameter in sensor development. Sensitivity is defined as the ratio between the output, dielectric change, and the input, RH change. In other words, it can be defined as an output capacitance change for a given change in input parameter, $\mathrm{RH}$. Therefore, $\frac{\partial \varepsilon_{F}}{\partial(R M)}$ can be taken as a measure of sensitivity. It is a partial derivative, as the transducer material exhibits sensitivities to other ambient or operating parameters. The gradient variation of $\mathrm{RH}$ vs capacitance (dielectric) graphs with frequency is given in Figure 7. It is obvious from the graph (Fig. 7) that the highest sensitivities can be achieved at the lowest frequencies, while with the increase of frequencies, sensitivity drops exponentially.

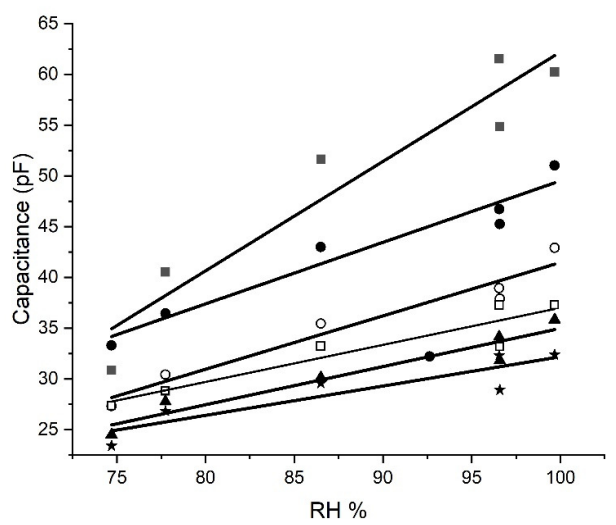

Figure 5: Capacitance variation with RH at different frequencies (solid squares $-50 \mathrm{~Hz}$, solid circles $-500 \mathrm{~Hz}$, hollow circles $-5000 \mathrm{~Hz}$, hollow squares $-50000 \mathrm{~Hz}$, solid triangles $-500000 \mathrm{~Hz}$, solid stars $-500000 \mathrm{~Hz}$ )

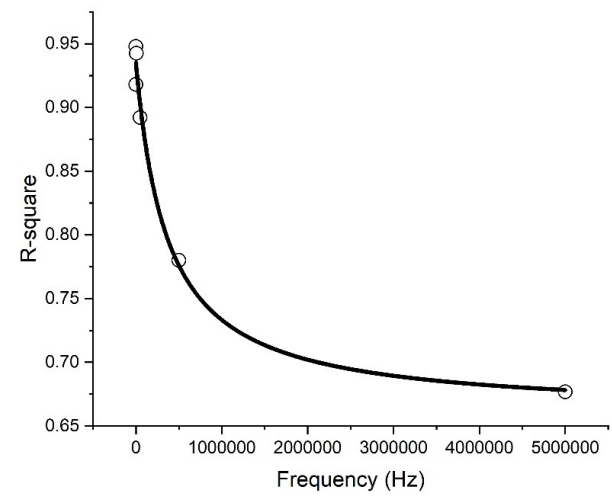

Figure 6: R-squared variation with frequency

These data suggest that damped RLC resonator circuits can be employed with the MCC sheet as a dielectric material for the capacitor in constructing humidity sensors. Such setup will allow monitoring temperature variations with the resistance variations and correct them.

\section{CONCLUSION}

Concepts, such as that of IoT, have created an immense demand for real-time data acquisition regarding the environment and the human body. The revolutionary advancement of

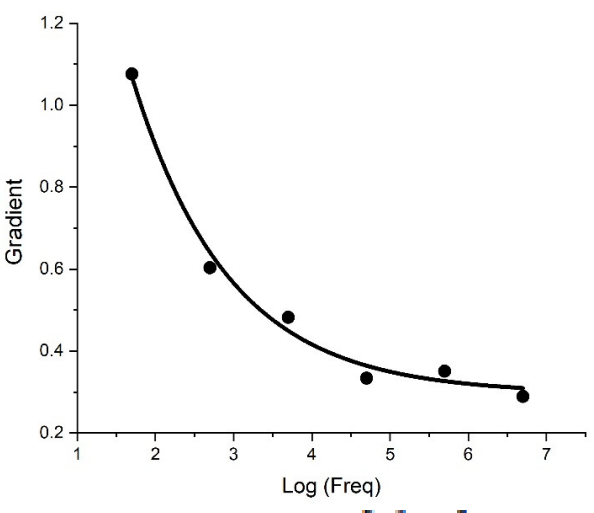

Figure 7: Variation of gradient $\left[\frac{\partial \varepsilon_{Y}}{\partial(R H)}\right] v s$ frequency

communication technology has made profound changes in the field of measurement systems. The points or locations that are not within reach can now be monitored in real-time. For such applications, it is necessary to identify potential transducer materials that can convert environmental changes to electrical signals.

In the current study, electrical properties of an MCC sheet were investigated to assess its suitability as a transducer material to convert $\mathrm{RH}$ changes to electrical signals. The capacitance of the MCC sheets has been found to be sensitive to 
moisture adsorption. The study results have demonstrated the potential of MCC as a transducer material to convert $\mathrm{RH}$ variations to electrical signals (in this case, dielectric constant values).

Generally, hot and humid tropical climates are the most challenging climatic zone, as far as humidity control is concerned. MCC exhibits sharper moisture adsorption behavior in the $\mathrm{RH}$ range of interest, making it a suitable candidate for humidity sensing. In addition, it was the investigation revealed that, at low frequencies, both the sensitivity and the accuracy of the transducer increases.

\section{REFERENCES}

1 S. A. Rankoana, Sustainability, 8, 221 (2016), https://doi.org/10.3390/su8030221

${ }^{2}$ P. Kanmani, J. Aravind, M. Kamaraj, P. Sureshbabu and S. Karthikeyan, Bioresour. Technol., 242, 295 (2017), https://doi.org/10.1016/j.biortech.2017.03.119

${ }^{3}$ I. A. Udoetok, L. D Wilson and J. V. Headley, ACS Appl. Mater. Inter., 8, $33197 \quad$ (2016), https://doi.org/10.1021/acsami.6b11504

${ }^{4}$ T. Zhang, L. Yang, X. Yan and X. Ding, Small, 14, 1802444

(2018), https://doi.org/10.1002/smll.201802444

${ }^{5}$ B. Peng, Z. Yao, X. Wang, M. Crombeen, D. G. Sweeney et al., Green Energ. Environ., 5, 37 (2020), https://doi.org/10.1016/j.gee.2019.09.003

${ }^{6}$ S. Palantöken, K. Bethke, V. Zivanovic, G. Kalinka, J. Kneipp et al., J. Appl. Polym. Sci., 137, 48380 (2020), https://doi.org/10.1002/app.48380

${ }^{7}$ L. Kreit, I. Bouknaitir, A. Zayne, M. E. Hasnaoui, M. E. Achour et al., J. Compos. Mater., 53, 2801 (2019), https://doi.org/10.1177/0021998319840420

${ }^{8}$ A. P. Mathew, K. Oksman and M. Sain, J. Appl. Polym. Sci., 97, $2014 \quad$ (2005), https://doi.org/10.1002/app.21779

${ }^{9}$ T. Zhao, Z. Chen, X. Lin, Z. Ren, B. Li et al., Carbohyd. Polym., 184, 164 (2018), https://doi.org/10.1016/j.carbpol.2017.12.024

10 C. C. Sun, J. Pharm. Sci., 94, 2132 (2005), https://doi.org/10.1002/jps.20459

${ }^{11}$ A. Kiziltas, D. J. Gardner, Y. Han and H. S. Yang, Thermochim. Acta, 519, 38 (2011), https://doi.org/10.1016/j.tca.2011.02.026

${ }^{12} \mathrm{~S}$. Naduparambath and E. Purushothaman, Cellulose, 23, 1803 (2016), https://doi.org/10.1007/s10570-0160904-3

${ }^{13}$ S. M. Bhasney, P. Bhagabati, A. Kumar and V. Katiyar, Compos. Sci. Technol., 171, 54 (2019), https://doi.org/10.1016/j.compscitech.2018.11.028

14 M. Rasheed, M. Jawaid, Z. Karim and L. C. Abdullah, Molecules, 25, $2824 \quad$ (2020), https://doi.org/10.3390/molecules25122824
${ }^{15}$ M. J. Tobyn, G. P. McCarthy, J. N. Staniforth and S. Edge, Int. J. Pharm., 169, 183 (1998), https://doi.org/10.1016/S0378-5173(98)00127-6

${ }^{16}$ D. Trache, M. H. Hussin, C. T. H. Chuin, S. Sabar, M. N. Fazita et al., Int. J. Biol. Macromol., 93, 789 (2016), https://doi.org/10.1016/j.ijbiomac.2016.09.056

${ }^{17}$ M. M. Haafiz, A. Hassan, Z. Zakaria and I. M. Inuwa, Carbohyd. Polym., 103, 119 (2014), https://doi.org/10.1016/j.carbpol.2013.11.055

${ }^{18}$ D. Bondeson, A. Mathew and K. Oksman, Cellulose, 13, 171 (2006), https://doi.org/10.1007/s10570-0069061-4

${ }^{19}$ A. Kiziltas, D. J. Gardner, Y. Han and H. S. Yang, J. Polym. Environ., 22, $365 \quad$ (2014), https://doi.org/10.1007/s10924-014-0676-5

${ }^{20}$ A. D. Fernandopulle, L. Karunanayake, A. M. P. B. Samarasekara, D. A. S. Amarasinghe and D. Attygalle, in Procs. MERCon Conference, July 28, 2020, pp. 205209, https://ieeexplore.ieee.org/document/9185348

${ }^{21}$ J. R. Capadona, K. Shanmuganathan, S. Trittschuh, S. Seidel, S. J. Rowan et al., Biomacromolecules, 10 , 712 (2009), https://doi.org/10.1021/bm8010903

${ }^{22}$ E. Psomiadou, I. Arvanitoyannis and N. Yamamoto, Carbohyd. Polym., 31, $193 \quad$ (1996), https://doi.org/10.1016/S0144-8617(96)00077-X

23 S. S. Z. Hindi, Nanosci. Nanotech. Res., 4, 17 (2017), https://doi.org/10.12691/nnr-4-1-3

${ }^{24}$ A. Wright, A. Marsh, F. Ricciotti, A. Shaw, F. Iza et al., Biomass Bioenerg., 118, 46 (2018), https://doi.org/10.1016/j.biombioe.2018.08.005

${ }^{24}$ Y. Feng, L. Xie, Q. Chen and L.-R. Zheng, IEEE Sens. J., $15, \quad 3201 \quad$ (2014), https://doi.org/10.1109/JSEN.2014.2385154

${ }^{26}$ G. T. Kohman, Ind. Eng. Chem., 31, 807 (1939), https://doi.org/10.1021/ie50355a005

${ }^{27}$ E. A. Campo, in "Selection of Polymeric Materials", edited by E. A. Campo, William Andrew Publishing, Norwich, NY, 2008, pp. 141-173

28 D. E. Kane, J. Polym. Sci., 18, 405 (1955), https://doi.org/10.1002/pol.1955.120188909

29 A. M. Abdel-Karim, A. H. Salama and M. L. Hassan, J. Phys. Org. Chem., 31, 3851 (2018), https://doi.org/10.1002/poc.3851

${ }^{30}$ P. Sethi and S. R. Sarangi, J. Electr. Comp. Eng., 1 (2017), https://doi.org/10.1155/2017/9324035

31 A. Radziwon, A. Bilberg, M. Bogers and E. S. Madsen, Procedia Eng., 69, 1184 (2014), https://doi.org/10.1016/j.proeng.2014.03.108

32 G. Niarchos, G. Dubourg, G. Afroudakis, M. Georgopoulos, V. Tsoutiet et al., Sensors, 17, 516 (2017), https://doi.org/10.3390/s17030516

${ }^{33}$ X. Wu, V. L. Chabot, B. K. Kim, A. Yu, R. M. Berry et al., Electrochim. Acta, 138, 139 (2014), https://doi.org/10.1016/j.electacta.2014.06.089

${ }^{34}$ T. T. L. Nguyen, N. Anton and T. F. Vandamme, in "Nanostructures for Oral Medicine", Elsevier, 2017, pp. 203-230, https://doi.org/10.1016/B978-0-32347720-8.00009-2 
${ }^{35}$ M. Zhang, J. Liu, J. Lv, Q. Chen, P. Qi et al., Cellulose, 25, $\quad 5611 \quad$ (2018), https://doi.org/10.1007/s10570-018-1988-8

${ }^{36}$ V. Ducéré, A. Bernès and C. Lacabanne, Sensor. Actuat. B-Chem., 106, $331 \quad$ (2005), https://doi.org/10.1016/j.snb.2004.08.028

${ }^{37}$ M. A. Najeeb, Z. Ahmad and R. A. Shakoor, $A d v$. Mater. Interfaces, 5, $1800969 \quad$ (2018), https://doi.org/10.1002/admi.201800969

38 J. F. Young, J. Appl. Chem., 17, 241 (1967), https://doi.org/10.1002/jctb.5010170901

${ }^{39}$ F. E. M. O'Brien, J. Sci. Instrum., 25, 73 (1948), https://doi.org/10.1088/0950-7671/25/3/305

${ }^{40}$ J. F. Young, J. Appl. Chem., 17, 241 (1967), https://doi.org/10.1002/jctb.5010170901

${ }^{41}$ A. Bismarck, I. Aranberri-Askargorta, J. Springer, T. Lampke, B. Wielage et al., Polym. Compos., 23, 872 (2002), https://doi.org/10.1002/pc.10485

${ }^{42}$ Y. Xie, C. A. Hill, Z. Jalaludin and D. Sun, Cellulose, $\quad \mathbf{1 8}, \quad 517 \quad$ (2011), https://doi.org/10.1007/s10570-011-9512-4

43 F. Y. Huang, Polymers, 4, 1012 (2012), https://doi.org/10.3390/polym4021012
${ }^{44}$ M. M. Haafiz, S. J. Eichhorn, A. Hassan and M. Jawaid, Carbohyd. Polym., 93, 628 (2013), https://doi.org/10.1016/j.carbpol.2013.01.035

${ }^{45}$ G. Varhegyi, E. Jkab and M. J. Antal, Energ. Fuel., 8, 1345 (1994), https://doi.org/10.1021/ef00048a025

${ }^{46}$ M. Nilsson and M. Strømme, J. Phys. Chem. B, 109, 5450 (2005), https://doi.org/10.1021/jp046991a

${ }^{47}$ S. Boutros and A. A. Hanna, J. Polym. Sci. Pol. Chem., $\quad \mathbf{1 6}, \quad 89 \quad$ (1978), https://doi.org/10.1002/pol.1978.170160109

${ }^{48}$ A. Wexler and S. Hasegawa, J. Res. Nat. Bur. Stand., 53, 19 (1954), https://doi.org/10.6028/jres.053.003

${ }^{49}$ A. Apelblat and E. Korin, J. Chem. Thermodyn., 30, 59 (1998), https://doi.org/10.1006/jcht.1997.0275

${ }^{50}$ M. C. León-Hidalgo, J. M. Gozálvez-Zafrilla, J. García and J. M. Arnal-Arnal, Desalin. Water Treat., 7, 111 (2009), https://doi.org/10.5004/dwt.2009.714

${ }^{51}$ J. F. Young, J. Appl. Chem., 17, 241 (1967), https://doi.org/10.1002/jctb.5010170901

${ }^{52} \mathrm{~S}$. Ummartyotin and H. Manuspiya, Renew. Sustain. Energ. Rev., 41, 402 (2015), https://doi.org/10.1016/j.rser.2014.08.050 